Original Research Article

\title{
Trends in antimicrobial susceptibility of blood culture-positive typhoid fever over half a decade in adults attending a tertiary care teaching hospital in South India
}

\author{
Mohammed Rafiuddin Rashed, Ashish Yadav*, Ramakrishna Pai Jakribettu
}

Department of Pharmacology, MES Medical College, Perinthalmanna, Kerala, India

Received: 09 September 2019

Revised: 10 October 2019

Accepted: 14 October 2019

*Correspondence to:

Dr. Ashish Yadav,

Email: dr.ashishyadav@ gmail.com

Copyright: () the author(s), publisher and licensee Medip Academy. This is an openaccess article distributed under the terms of the Creative Commons Attribution NonCommercial License, which permits unrestricted noncommercial use, distribution, and reproduction in any medium, provided the original work is properly cited.

\begin{abstract}
Background: Typhoid fever is a public health concern in developing countries. Developed countries have also been influenced due to tourism. The drugs used for treating typhoid fever can and have been rendered unusable due to resistance. Monitoring and updating the Salmonella antibiogram is needed to prevent therapeutic failures. This study confirms to the same goal.

Methods: This study was conducted retrospectively in a tertiary care hospital in North Kerala with data collected from 2013 to 2017. Years were categorized into four quarters to analyze seasonality. Positive blood culture samples of adults, identified to be Salmonella typhi or paratyphi were subjected to antimicrobial sensitivity.

Results: 37 Salmonella isolates were included. July-September quarter was found to have maximum incidence of typhoid fever followed by April-June quarter. All isolates were $100 \%$ sensitive to ceftriaxone, chloramphenicol, and amoxicillin-clavulanic acid. Sensitivity lacked for nalidixic acid (48.65\%), ciprofloxacin $(48.65 \%)$ and levofloxacin $(70.27 \%)$. Sensitivity to ampicillin and cotrimoxazole was $86.49 \%$ and $91.89 \%$. Azithromycin efficacy was good overall $(94.59 \%)$ with resistant isolates emerging in final year of this study.

Conclusions: Monsoon is most conducive for typhoid fever occurrence followed by summer. This study confirms utility of ceftriaxone and futility of quinolones and fluoroquinolones in typhoid fever treatment. Azithromycin has started showing emergence of resistance. Ampicillin and cotrimoxazole cannot be relied upon due to variability in sensitivity patterns. Chloramphenicol showed full efficacy throughout the study period which is encouraging. Amoxicillin-clavulinic acid, surprisingly was $100 \%$ effective throughout study period. However, no contemporary data is available for comparison.
\end{abstract}

Keywords: Salmonella, Typhoid, India, Resistance, Sensitivity, Amoxicillin

\section{INTRODUCTION}

In developing countries, typhoid fever has been a major health problem on account of poor socioeconomic status compounded by poor sanitation facilities. According to recent estimates, Asian countries see 12-20 million cases and 13000-22000 deaths per year due to typhoid fever. ${ }^{1}$ The figures for India estimate the typhoid fever incidence at 493.5/100000 persons per year with $340.1 / 100000$ per person per year of these cases occurring in children of age group 2-5. ${ }^{2}$ Most recent systematic reviews place the pooled estimates of annual incidence of Typhoid fever due to S. typhi and S. paratyphi at 377 and 105 cases/100000 persons per year respectively. ${ }^{3}$

Typhoid fever, if untreated with appropriate antimicrobial agents, can lead to complications thus prolonging morbidity. Ciprofloxacin, which used to be the drug of choice till recent times is no longer recommended as a line of treatment due to resistance in most places. Also the current recommendation for hospitalized patients, i.e., ceftriaxone, though effective at present, is showing a trend towards resistance with increasing minimum inhibitory concentration (MIC) values. ${ }^{4,9}$ This emphasizes 
the need for constant vigilance of the antibiogram so that the timely recommendations for the most optimum drug can be applied into practice and the ineffective drug can be taken out of the regimen.

Keeping in view, the need for regular monitoring of organism susceptibility towards anti-microbials for optimal pharmacotherapy and successful outcomes, this study was undertaken to analyze the changing trends in $S$. typhi and $S$. paratyphi susceptibility to current antimicrobials and timely prediction of more effective antimicrobial/s that may need to be employed.

\section{METHODS}

This retrospective study was carried out in MES Medical College Hospital, Perinthalmanna, which is a 570-bedded multi-specialty tertiary care teaching hospital situated in Malappuram district in North Kerala. The data for this study was retrospectively collected from January 2013 to December 2017. Due clearance from the institutional ethics committee was obtained before commencing the study.

The blood samples of patients above 18 years of age during the study period which were flagged positive by the automated blood culture system (BACTEC 9050) were included as denominator for calculation of incidence in this study. Repeat isolates were excluded. The positive samples underwent preliminary identification by Gram staining and definitive identification by culture on blood and McConkey agar. ${ }^{5}$
Those samples which were identified as $S$. typhi and $S$. paratyphi were subjected to antimicrobial sensitivity testing by Kirby-Bauer disc diffusion method according to CLSI guidelines of the corresponding period. ${ }^{6-8}$ Following antimicrobials were tested for sensitivity: ampicillin, amoxicillin-clavulanic acid, ceftriaxone, cotrimoxazole, nalidixic acid, ciprofloxacin, levofloxacin, azithromycin, chloramphenicol.

The month and year of presentation were recorded. The years were categorized into four quarters of three months each to observe seasonality of typhoid fever. Also, the year-wise sensitivity data was used to infer trends in pattern of sensitivity over the study period.

Data tabulation, analysis and graphical representation were done with the help of Microsoft Office Excel and Word 2007 software.

\section{RESULTS}

\section{Incidence}

During the study period, a total of 14153 blood samples were received for blood culture of which 1316 were reported positive for bacterial growth by the BACTEC system. The positive samples were identified for S. typhi or $S$. paratyphi in a total of 37 cases over five year study period. The incidence rate of culture positive typhoid fever was calculated to be $2.81 \%$ of all bacterial growth positive samples for the five year period (Table 1).

Table 1: Year-wise incidence of Salmonella positive blood culture during the study period.

\begin{tabular}{|lllll|}
\hline Year & Total samples & $\begin{array}{l}\text { Bacterial growth } \\
\text { positive samples }\end{array}$ & $\begin{array}{l}\text { Salmonella species } \\
\text { positive samples }\end{array}$ & \begin{tabular}{l} 
\% positivity of Salmonella \\
\hline $\mathbf{2 0 1 3}$
\end{tabular} \\
\hline $\mathbf{2 0 1 4}$ & 1943 & 132 & 2 & 1.52 \\
\hline $\mathbf{2 0 1 5}$ & 2039 & 153 & 5 & 3.27 \\
\hline $\mathbf{2 0 1 6}$ & 3510 & 290 & 10 & 3.45 \\
\hline $\mathbf{2 0 1 7}$ & 3269 & 245 & 9 & 3.67 \\
\hline Overall & 3392 & 496 & 11 & 2.22 \\
\hline
\end{tabular}

Table 2: Year-wise \% sensitivity of Salmonella isolates to antimicrobials.

\begin{tabular}{|c|c|c|c|c|c|c|c|c|c|c|}
\hline \multirow[b]{2}{*}{ Year } & \multirow[b]{2}{*}{$\begin{array}{l}\text { Total } \\
\text { Salmonella } \\
\text { positive } \\
\text { blood } \\
\text { culture } \\
\text { isolates }\end{array}$} & \multicolumn{9}{|c|}{$\%$ of isolates sensitive to antimicrobials } \\
\hline & & $\begin{array}{l}\text { Ampi- } \\
\text { cillin }\end{array}$ & $\begin{array}{l}\text { Amoxicillin- } \\
\text { clavulanic } \\
\text { acid }\end{array}$ & $\begin{array}{l}\text { Ceftri- } \\
\text { axone }\end{array}$ & $\begin{array}{l}\text { Cotrimo- } \\
\text { xazole }\end{array}$ & $\begin{array}{l}\text { Nalidixic } \\
\text { acid }\end{array}$ & $\begin{array}{l}\text { Cipro- } \\
\text { floxacin }\end{array}$ & $\begin{array}{l}\text { Levo- } \\
\text { floxacin }\end{array}$ & $\begin{array}{l}\text { Azithro- } \\
\text { mycin }\end{array}$ & $\begin{array}{l}\text { Chloram- } \\
\text { phenicol }\end{array}$ \\
\hline 2013 & 2 & 50 & 100 & 100 & 100 & 100 & 100 & 100 & 100 & 100 \\
\hline 2014 & 5 & 100 & 100 & 100 & 100 & 100 & 100 & 100 & 100 & 100 \\
\hline 2015 & 10 & 90 & 100 & 100 & 100 & 50 & 50 & 90 & 100 & 100 \\
\hline 2016 & 9 & 66.67 & 100 & 100 & 77.78 & 55.56 & 55.56 & 100 & 100 & 100 \\
\hline 2017 & 11 & 100 & 100 & 100 & 90.91 & 9.09 & 9.09 & 9.09 & 81.82 & 100 \\
\hline Overall & 37 & 86.49 & 100 & 100 & 91.89 & 48.65 & 48.65 & 70.27 & 94.59 & 100 \\
\hline
\end{tabular}

All Salmonella isolates, in the five year study period, and were found to be sensitive to amoxicillin-clavulanic acid, ceftriaxone and chloramphenicol. 


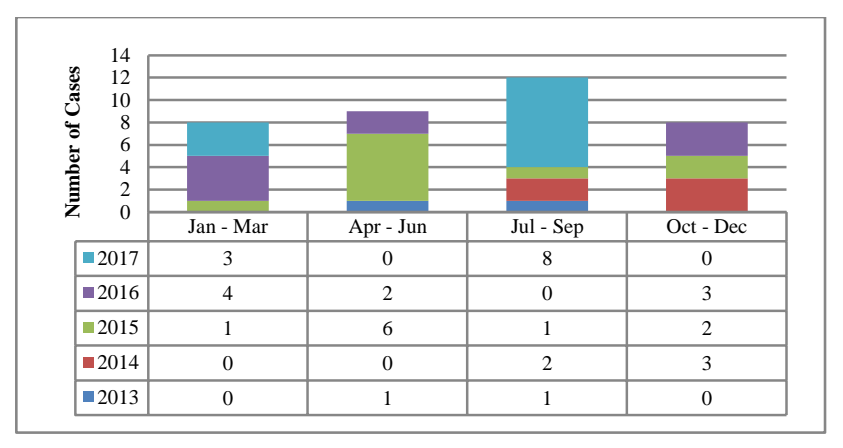

Figure 1: Seasonal trends in blood culture Salmonella positive typhoid fever during the study period.

Quarter of July to September witnessed maximum such cases followed by the quarter of April to June.

The individual yearly figures of cases positive for Salmonella species were 2, 5, 10, 9 and 11 for the years 2013 thru 2017 respectively.

\section{Seasonality}

Overall, in the five year study period, the quarter from July to September was found to be the period of maximum presentation of blood culture-positive typhoid fever wherein 13 out of all 37 cases presented followed by the quarter April to June, which witnessed 9 cases overall (Figure 1).

\section{Anti-microbial susceptibility}

In the five year study period, all 37 Salmonella isolates were found to be susceptible to amoxycillin-clavulanic acid, ceftriaxone and chloramphenicol. Azithromycin and cotrimoxazole also had a good antimicrobial effect with more than $90 \%$ of all isolates susceptible to these drugs. Ampicillin was effective in about $85 \%$ of the isolates while quinolone (nalidixic acid) and fluoroquinolones (ciprofloxacin and levofloxacin) proved to be less effective (Table 2).

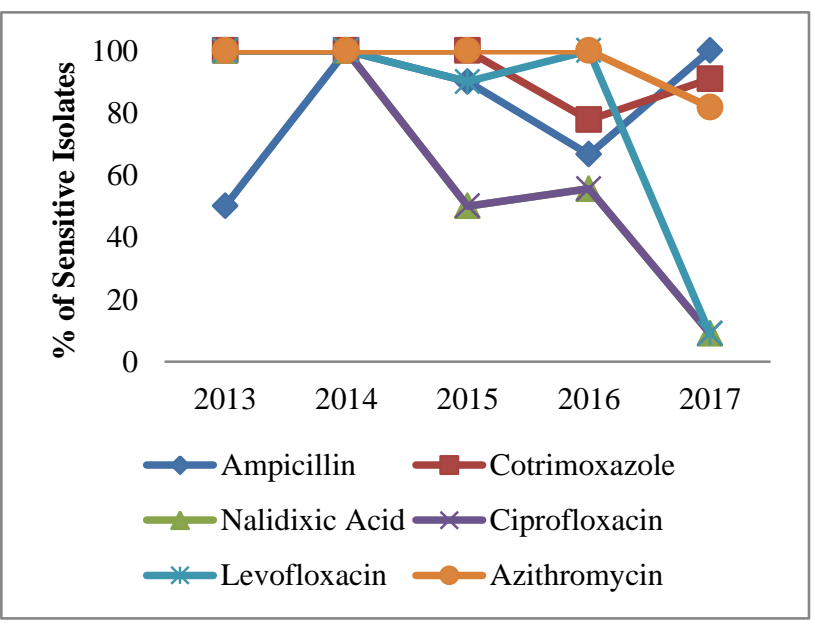

Figure 2: Salmonella sensitivity to antimicrobials over the study period.
Sensitivity to quinolone and fluoroquinolones shows a sharp decline of late. (Antimicrobials to which isolates remained sensitive throughout viz., amoxicillinclavulanic acid, ceftriaxone and chloramphenicol have not been included in figure for cleaner representation).

\section{DISCUSSION}

That, the importance of typhoid fever as a health concern is limited to developing nations, would be an understatement. In this era of globalization and globetrotting population, the importance of typhoid fever applies as much to the developed countries as it applies to the developing countries hosting the international travelers. This threat is compounded by the fact that Salmonella has developed resistance to drugs which were used as drugs of first choice till recently. Therefore, the need for a constant vigil of the antibiogram of this genus is a general mandate to formulate preventive as well as curative strategies.

Out of 1316 blood cultures positive for bacterial growth, 37 were identified to be Salmonella species in this study, thus making the overall incidence to be $2.81 \%$ (Table 1). Similar such studies in India, have reported the incidence to be from $<1$ to $5 \%{ }^{9-11}$

In this study, although there was no time of the year which can be said to be free from occurrence of typhoid fever, there are, indeed, times which have greater incidence of this disease than others. Overall, the quarter of July to September was found to be most conducive for Salmonella followed by the quarter of April to June (Figure 1). When individual years are observed, the season of maximum incidence is noted to be not absolute or fixed. However, the general pattern of maximum incidence of typhoid fever in summer and monsoon months in India is predominant. Sharma et al from North India also report the quarter July to September to be the period of occurrence of most cases of typhoid fever followed by the quarter of April to June with some undulation in individual years. ${ }^{9}$ This is in excellent agreement with what has been observed in this study. Similarly, Bhattacharya et al in a study from Eastern part of India also note the maximum incidence of typhoid fever between March and July. ${ }^{11}$ This study from South India correlates very well with studies from other parts of India which also note the seasons of maximum incidence to be summer and monsoon months for typhoid fever. The reason for increased incidence during the summer months can be attributed to decreased water availability during which contaminated stagnated water is likely to be utilized. Monsoon incidence increase can be explained by wider dissemination of the causative agents.

The change in the antibiogram of Salmonella observed in this study over five years is remarkable as it captured the appearance and dissemination of strains of Salmonella resistant to the drugs acting on DNA gyrase viz., quinolones and fluoroquinolones which were the drugs of 
first choice against this organism till recent times (Table 2, Figure 2). In this study, the Salmonella isolates totally sensitive to quinolones and fluoroquinolones till 2014. Following year, the sensitivity suddenly dropped to $50 \%$ and remained so in 2016 also. However, in 2017, the sensitivity fall was again sudden and drastic so that only about $9 \%$ of isolates remained sensitive. Similar data has been captured by other studies across India wherein Salmonella was usually sensitive to Fluoroquinolones until five years back. ${ }^{11,12}$ All recent studies report Salmonella to be now resistant to this class of drugs and which is now no longer recommended for treatment of typhoid fever. , $^{90,13}$

Ampicillin sensitivity has been variable. Many studies have reported the susceptibility of Salmonella to ampicillin to range from $<50 \%$ to more than $90 \%$. $^{10-12}$ In this study, Ampicillin efficacy was found to be about $85 \%$ overall, nevertheless essentially erratic over the years of the study period. All isolates were found to be sensitive in 2014 and 2017 in this study while a good deal of resistance was observed in other years of the study period (Table 2). Likewise, including Ampicillin in therapeutic regimen for typhoid fever would not, currently, be advisable.

A surprising, exciting and potentially game-changing finding in this study was the complete susceptibility of Salmonella isolates to amoxicillin-clavulanic acid, consistently throughout the study period of five years (Table 2). Amoxicillin either alone or in combination with clavulanic acid had a good utility in 1970s and 80s where after the use declined due to development of resistance. $^{15,16}$ A recent Indian study conducted over a decade has indicated the trends of sensitivity restoration to amoxicillin alone. ${ }^{9}$ However, contemporary data on effectiveness of amoxicillin-clavulanic acid for S. typhi and paratyphi are largely lacking both in Indian context and internationally. It would be interesting to see other authors taking up MIC value studies on amoxicillinclavulanic acid on the two studied Salmonella serotypes to confirm or debunk the findings of this study which potentially points to probable redeployability of this drug combination in near future.

The susceptibility of Salmonella species to cotrimoxazole was found to be $91.89 \%$ overall (Table 2) and agrees with recent such studies which report the figure of $90 \%$ or higher susceptibility with some variation in individual years. ${ }^{9,10,17}$ The utility of this drug at present and in near future cannot be assuringly commented upon with such variability in susceptibility patterns.

Ceftriaxone, the current drug of choice for seriously ill in-patients of Typhoid fever, was found to uphold its track record in this study too, with Salmonella being $100 \%$ susceptible throughout the study period. Some authors have casted a legitimate concern on the rising MIC values of this drug in the recent years. ${ }^{4,9}$ Also ceftriaxone resistance has been reported in India in a treatment-naïve patient. ${ }^{14}$ Hence, ceftriaxone requires a continuous close watch in the current scenario for monitoring its utility in typhoid fever.

Azithromycin, which showed an excellent sensitivity all through, displayed emergence of some resistance in the final year of the study period viz., 2017 (Table 2, Figure 2) with overall sensitivity of $94.59 \%$. Recent studies have also indicated varying susceptibility ranging from upward of $90 \%$ to less than $50 \% .^{9,12,17}$ This is a worrisome trend given that azithromycin is considered the alternative oral treatment in non-serious typhoid fever patients.

Many studies overtime have captured gradual restoration of chloramphenicol susceptibility in Salmonella since $2000 .^{18}$ Since 2009 onwards, many consistent reports of chloramphenicol susceptibility more than $90 \%$ have been published with most recent studies reporting almost consistent $100 \%$ susceptibility. ${ }^{9-12,17,19}$ This study also confirms the restored susceptibility to chloramphenicol (Table 2) in agreement with the latest reports. Consistent with these trends, the medical fraternity might see this drug reclaiming its lost glory in all likelihood in very near future.

\section{CONCLUSION}

The study agrees with other such studies from other parts of the country on the seasonality of typhoid fever in India. It reports similar trends in Salmonella susceptibility to antimicrobials as reported from various parts of India and also contributes to the corpus of such available data. However, the major find of this study has been complete susceptibility of Salmonella species to amoxicillin-clavulanic acid across the five years of study. This finding, if corroborated by other researchers, shall add one more useful weapon in our armamentarium against typhoid fever as well as bring simplicity in the management of typhoid fever, at least on the out-patient basis.

\section{Funding: No funding sources \\ Conflict of interest: None declared \\ Ethical approval: The study was approved by the Institutional Ethics Committee}

\section{REFERENCES}

1. Mogasale V, Maskery B, Ochiai RL, Lee JS, Mogasale VV, Ramani E, et al. Burden of typhoid fever in low-income and middle-income countries: a systematic, literature-based update with risk-factor adjustment. Lancet Global Health. 2014;2(10):e57080 .

2. Ochiai RL, Acosta CJ, Danovaro-Holliday MC, Baiqing D, Bhattacharya SK, Agtini MD, et al. A study of typhoid fever in five Asian countries: disease burden and implications for controls. Bull World Health Organ. 2008;86:260-8. 
3. John J, Van Aart CJC, Grassly NC. The Burden of Typhoid and Paratyphoid in India: Systematic Review and Meta-analysis. Baker S, editor. PLoS Neg1 Trop Dis. 2016;10(4):e0004616.

4. Dahiya S, Sharma P, Kumari B, Pandey S, Malik R, Manral N, et al. Characterisation of antimicrobial resistance in Salmonellae during 2014-2015 from four centres across India: an ICMR antimicrobial resistance surveillance network report. Indian J Med Microbiol. 2017;35(1):61.

5. Collee JG, Miles RS, Watt B. Tests for the identification of bacteria. In: Collee JG, Fraser AG, Marmion BP, Simmons A, eds. Mackie and McCartney Practical Medical Microbiology. 14th ed. London: Churchill Livingstone; 1996: 131-149.

6. Clinical and Laboratory Standards Institute. Performance Standards for Antimicrobial Susceptibility Testing; Twenty-Second Informational Supplement. CLSI Document M100-22. Wayne, PA: Clinical and Laboratory Standards Institute; 2012.

7. Clinical and Laboratory Standards Institute. Performance Standards for Antimicrobial Susceptibility Testing; Twenty-Third Informational Supplement. CLSI Document M100-23. Wayne, PA: Clinical and Laboratory Standards Institute; 2013.

8. Clinical and Laboratory Standards Institute. Performance Standards for Antimicrobial Susceptibility Testing; Twenty-Fifth Informational Supplement. CLSI Document M100-25. Wayne, PA: Clinical and Laboratory Standards Institute; 2015.

9. Sharma P, Dahiya S, Manral N, Kumari B, Kumar S, Pandey S, et al. Changing trends of culture-positive typhoid fever and antimicrobial susceptibility in a tertiary care North Indian Hospital over the last decade. Indian J Med Microbiol. 2018;36(1):70.

10. Singh L, Cariappa MP. Blood culture isolates and antibiogram of Salmonella: experience of a tertiary care hospital. Med J Armed Forces India. 2016;72(3):281-4.

11. Bhattacharya SS, Das U, Choudhury BK. Occurrence and antibiogram of Salmonella typhi and S. paratyphi A isolated from Rourkela, Orissa. Indian J Med Res. 2011;133(4):431-3.
12. Choudhary A, Gopalakrishnan R, Senthur NP, Ramasubramanian V, Ghafur KA, Thirunarayan MA. Antimicrobial susceptibility of Salmonella enterica serovars in a tertiary care hospital in southern India. The Indian J Med Res. 2013;137(4):800.

13. Sharma P, Dahiya S, Kumari B, Balaji V, Sood S, Das BK, et al. Pefloxacin as a surrogate marker for quinolone susceptibility in Salmonella enterica serovars typhi paratyphi A in India. Indian $\mathbf{J}$ Med Res. 2017;145(5):687.

14. Gokul BN, Menezes GA, Harish BN. ACC-1 $\beta$ Lactamase-producing Salmonella enterica serovar Typhi, India. Emerg Infect Dis. 2010;16(7):1170-1.

15. Nolan CM, White PC. Treatment of typhoid carriers with amoxicillin. Correlates of successful therapy. JAMA. 1978;239(22):2352-4.

16. Dolna I, Gosciniak G, Ruczkowska J. Sensitivity of Salmonella strains to augmentin and new generation cephalosporins and aminoglycosides. Przegl Epidemiol. 1989;43(2):218-22.

17. Sania KM, Shyamasakhi PD, Pramodini KD, Sulochana KD. Evaluation of minimum inhibitory concentration of chloramphenicol for Salmonella spp. Isolated from enteric fever cases in a tertiary hospital in Imphal. Int J Pharm Sci Res. 2016;7(9):3815-19.

18. Mohanty S, Renuka K, Sood S, Das BK, Kapil A. Antibiogram pattern and seasonality of Salmonella serotypes in a North Indian tertiary care hospital. Epidemiol Infect. 2006;134(5):961-6.

19. Ramesh U, Das S, Balasubramanian A. Reemergence of chloramphenicol-susceptible Salmonella typhi and Paratyphi A strains in India. Indian J Med Microbiol. 2016;34(2):262.

Cite this article as: Rashed MR, Yadav A, Jakribettu RP. Trends in antimicrobial susceptibility of blood culture-positive typhoid fever over half a decade in adults attending a tertiary care teaching hospital in South India. Int J Basic Clin Pharmacol 2019;8:2523-7. 